\title{
Modelling for degreasing the mining equipment downtime by optimizing blasting period at Erdenet surface mine
}

\author{
Khavalbolot Kyelgyenbai ${ }^{1, *}$, Serhii Pysmennyi ${ }^{2}$, Serhii Chukharev ${ }^{3}$, Batbolor Purev ${ }^{4}$, and Ijilmaa Jambaa ${ }^{1}$ \\ ${ }^{1}$ Mongolian University Science and Technology, Baga Toiruu 34, Sukhbaatar District, Ulaanbaatar, Mongolia \\ ${ }^{2}$ Kryvyi Rih National University, 11 Vitaly Matusevich Str., Kryvyi Rih, 50027, Ukraine \\ ${ }^{3}$ National University of Water Management and Nature Resources Use, 11 Soborna Str., Rivne, 33028, Ukraine \\ 4“Erdenet Industry” State Owned Enterprise, Bayanundur sum, Orkhon province, Mongolia
}

\begin{abstract}
Erdenet copper-molybdenum deposit is the biggest one in the world and has a significant impact on Mongolian society and economy. Today LIEBHERR-994B hydraulic shovels from Germany, electric shovels including EKG-10 and EKG-15 from Russia operate for the mining works, and dump truck BelAZ 75130 used for transportation. The causes of shovel downtime are classified as technical, technological, and organizational. During the study period, $41 \%$ of the total downtime of the excavator's park was technical, $45 \%$ was technological, and $11 \%$ was organizational downtime. For shovels, $7 \%$ of technological downtime is due to blasting, and for dump trucks $8.7 \%$. In open-pit mining, blasting is performed on a weekly basis, so the duration of this technological downtime can be considered almost constant. If the time between blasts or period of blasting can be arranged optimally, it will be possible to reduce mining equipment's downtime due to blasting.
\end{abstract}

\section{Introduction}

The mining industry in Mongolia is one of the leading sectors that determine the country's economic development. The continues and efficient operation of any mining enterprise is inextricably defined with the operating costs of mining equipment, including a shovels, a dump trucks and a drilling rigs.

Operating costs are mainly dependent on the reliability of the equipment and its exploitation management. Following the growth of the world's population and the demand for mineral products, Mongolia's mining and processing sector are rapidly developing on a large scale, captivating large amounts of foreign and domestic investment. Hence, the mining sector income for approximately 30 percent of Mongolia's budget and plays the main role in the economy in terms of employment and production [1].

Due to the high capital expenditures and operation expenditure of any mining industry, continuous operation and economic efficiency depend on the proper organization of each mining process and the equipment exploitation management. Especially, it is essential to enhance profitability by increasing the utilization rate of dump trucks and shovels, which account for more than 70 percent of the total operating costs of the mining industry and reducing costs [1].

Under certain operating conditions, the profitability of a mining machinery depends on its reliability, technology, and maintenance. These parameters and factors interact with the end result of the machine's operation. In other words, maintenance costs depend on the level of reliability, on the other hand, reliability depends on the level of operation.

Therefore, in order to improve the service life of the mining machine, comprehensive research has been carried out to determine the level of reliability and technological quality during its operation, the quality of the maintenance system, and the economic viability [2].

As noted above, as Mongolia's investment and foreign relations in the mining sector expand, the use of mining machinery manufactured in Germany, the United States, the Republic of Korea, and Japan is increasing. Today, not only mining machinery manufactured in these countries but also machinery manufactured in Russia have a high level of reliability of electrical and mechanical systems based on the previous base, ergonomic problems are fully solved, equipped with diagnostic equipment, work performance information system, mechanisms, and assembly units. The operations are fully automated and manufactured at the smart machine with a high level of mechatronics $[3,4,5]$.

Research and study have been performed to improve the operation and reliability level and the optimization of the process of the industry's open-pit shovelss and dump trucks, but it must be kept up to date with current technological advances.

"Erdenet Industry" state-owned corporation is one of the largest mining and processing plant in Mongolia. Nowadays, the depths of the Erdenet open-pit mine have been changed from $1,500 \mathrm{~m}$ to $1,265 \mathrm{~m}$, and the experience of similar mines around the world shows that when the

\footnotetext{
* Corresponding author: khavalbolot@must.edu.mn
} 
average transportation distance of mining rock and ore is more than $10 \mathrm{~km}$ and the depth of the mine is more than $100 \mathrm{~m}$, operating costs increase and production efficiency decreases. Due to the increasing depth and transportation distance of mining rock mass of the Erdenet open-pit mine and the declining ore grade of the deposit, the cost of mining and concentrate processing is increasing every year.

The following equipment is used for the mechanization of Erdenet open pit mining and the approach is expected to use this type of equipment until 2036 years:

\section{$>$ Shovels:}

- EKG15 from Russia

○ Liebherr-994B from Germany

\section{$>$ Dump trucks:}

$$
\text { ○ BelAZ } 75130
$$

$>$ Drilling rigs:

$$
\text { ○ SBSh-250MNA. }
$$

As a result of the analysis of the exploitation level of shovelss using at the Erdenet open-pit mine, the numerical values of the main parameters of their reliable operation were determined and the average level for the park is shown in Table 1.

Table 1. Shovels park reliability indicators.

\begin{tabular}{|l|c|}
\hline \multicolumn{1}{|c|}{ Reliability indicators } & $\begin{array}{c}\text { Average } \\
\text { value }\end{array}$ \\
\hline Mean time between failure, hours & 432 \\
\hline Availability ratio & 0,768 \\
\hline Technical utilization rate & 0,642 \\
\hline Failure flow parameters, 1/hours & 0,002315 \\
\hline Average recovery time, hours & 43,4 \\
\hline $\begin{array}{l}\text { Specific duration of unplanned repair, } \\
\text { hours/hours }\end{array}$ & 0,0993 \\
\hline
\end{tabular}

In order to assess the general level of the electrical shovel and dump truck utilization, the volume of the excavated and transported rock mass is shown for each type of shovels using at the Erdenet open-pit mine (Figure 1).

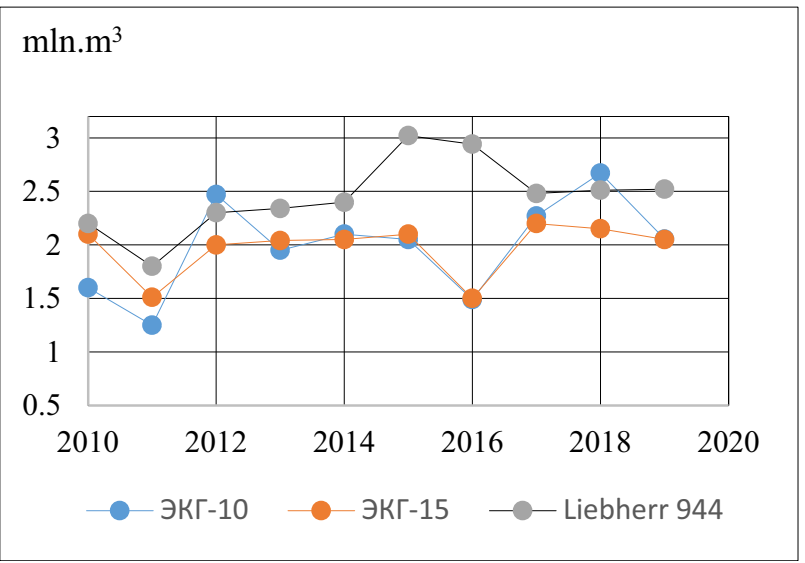

Fig. 1. Shovels' productivity by per year.

The increase in the shovels' productivity may be due to enhanced concentrator capacity. But, makes it impossible to conclude that equipment utilization has increased or downtime has decreased.

The average calendar time utilization factor for shovelss used in open pit mining is 0.75 . The study defined that in the case of an shovels park, planned downtime accounts for the majority of total downtime, but it is necessary to analyze the causes of unplanned downtime to determine for opportunities to improve utilization and further study mining equipment reliability.

In general, the operation and productivity of shovels, which are the main machines in the mining industry, on the one hand, depends on the weather condition, technical state, and technological activities, the other hand, it directly affects the operation and downtime of other technological machines, such as dump trucks.

Therefore, based on the dispatcher's data, the causes for the downtime of the shovels are shown in Figure 2. It is clear from Figure 2 that $41 \%$ of the total downtime of the shovels park during the study period was technical, $45 \%$ was technological, $11 \%$ was organizational downtime and $3 \%$ was other causes [1].

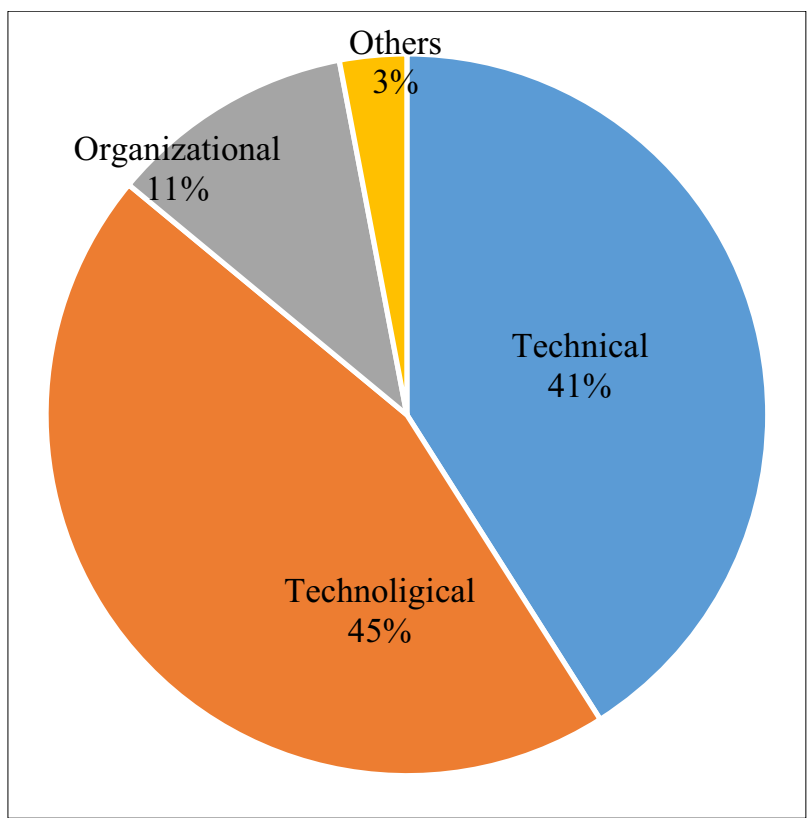

Fig. 2. The causes and types of shovel park downtime.

The causes of downtime related to the technical and technological operation and organization of shovels are classified as follows.

- The causes of downtime related to the technical:

- Repair

- Maintenance of one year

- Planned maintenance

- Unplanned maintenance due to mechanical failure

- Unplanned maintenance due to electrical failure

- Technical service due to mechanical part

- Technical service due to electrical part

O Others

- The causes of downtime related to the technological operation: 


$\begin{array}{cc}\circ & \text { The processing plant cannot accept ore } \\ \circ & \text { without operator } \\ & \text { without dump trucks }\end{array}$

- The causes related to the organization:

- due to change shovels working position

$\circ$ due to blasting

- due to averaging and blending ore

During the study period, $55 \%$ of the total downtime due to the organization of the shovel was caused by the processing plant and $44 \%$ was due to without dump trucks (Figure 3).

Due to the close relationship between concentrator operations and open-pit mining, as of 2005, 36\% of technology-related downtime was due to blasting operations, $39 \%$ due to averaging and blending ore, and $25 \%$ due to change the working position of shovels. As of $2020,7 \%$ of technology downtime is due to blasting, $89 \%$ to averaging and blending ore, and $4 \%$ due to change shovel's working position (Figure 4).

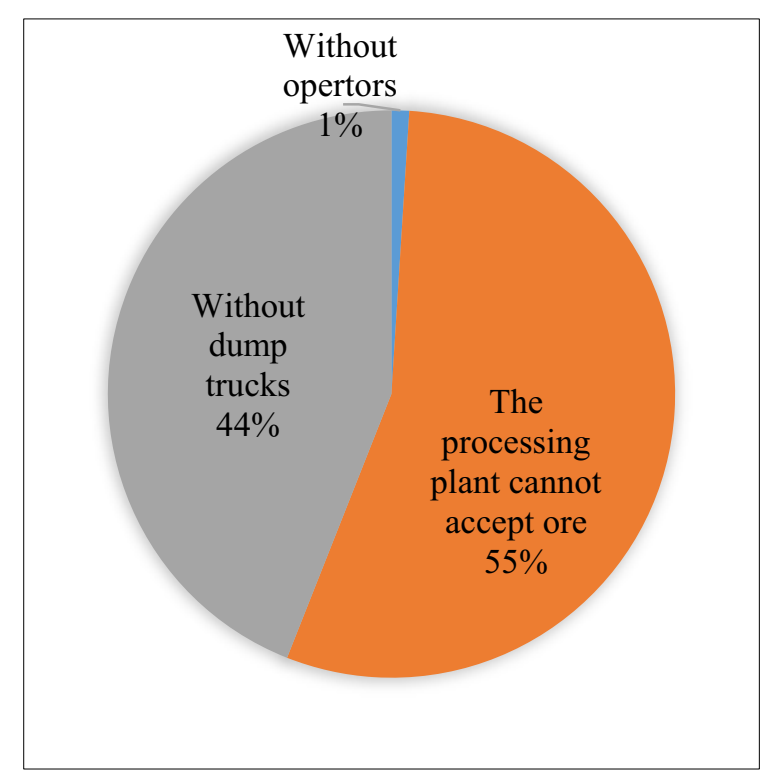

Fig. 3. The causes and types of total downtime due to the organization of the shovel.

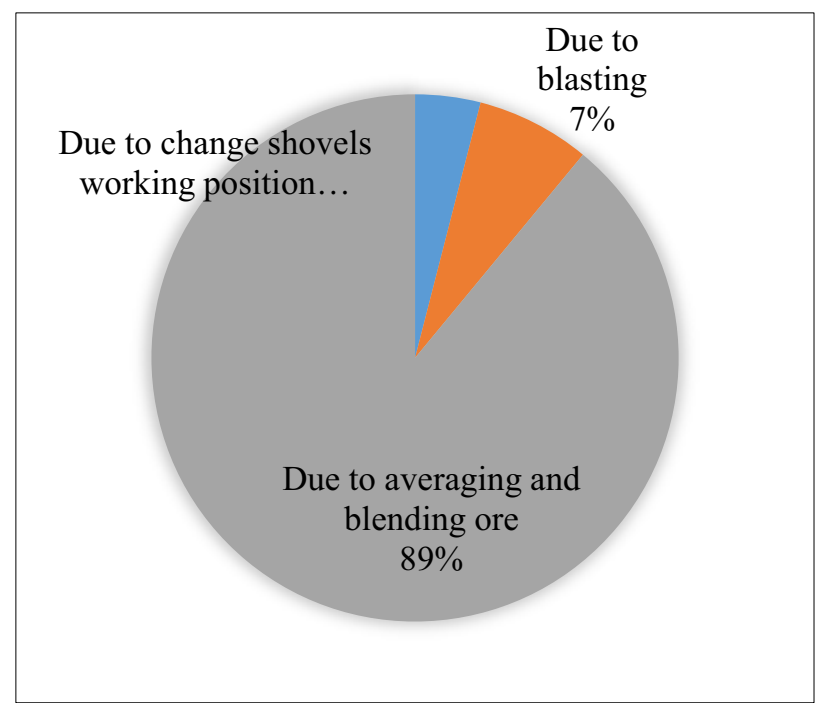

Fig. 4. The causes and types of technological downtime of the shovel.
These technological downtimes can be considered almost constant, as blasting is carried out on a weekly in the Erdenet open-pit mine, and changing the shovels working position are performed based on mining plaining and progresses. As blasting is a high-risk process, all machinery and equipment are immediately shut down to blast at the mine. The duration of blast-induced downtime is usually $1 \ldots 2$ hours, but is very high in terms of cumulative downtime value for all mining equipment throughout the year.

Blasting is one of the most important operations in mining extraction, the purpose of drilling and blasting is to break and prepare the fragmented rocks for digging and transportation process. In the mining industry, the volume of the rock mass to be blasted per year is determined by the productivity of mining, which is one of the main parameters for selecting drilling rigs according to the rock hardness of the deposit and the bucket of shovels $[6,7,8]$. In addition to determining the number of blasts to be carried out per year and the cost of preparing $1 \mathrm{~m}^{3}$ of the rock mass for excavation and transportation work, one of the downtime's causes of mining equipment is blasting operation.

The blasting at the Erdenet surface mine is carried out every Friday at $3 \mathrm{pm}$, with a signal at $2 \mathrm{pm}$ to ensure the safety of workers at the open-pit and to stop all mining operations for approximately 1.2 to 1.9 hours. According to a study of the mining equipment included shovels and dump trucks, the average duration of downtime due to blasting is on average $13-28.9 \%$ just for the shovels's park. Therefore, let's consider the level of downtime due to blasting operations for the mining equipment [6].

\section{Research methods}

When the number of shovels in the shovels's park is 8 working at the Erdenet mine, the duration of downtime varies depending on the blasting operation, with a maximum of 865 hours and a minimum of 664 hours per year, and just for a shovel with a maximum of 93.1hours and a minimum of 83 hours (Table 1).

It is also clear from Table 1 that this phenomenon is observed in the dump truck's park [6].

Table 1. The duration of downtime for the shovels and the dump trucks, due to the blasting work.

\begin{tabular}{|l|c|l|l|l|}
\hline \multirow{2}{*}{$\begin{array}{c}\text { The blasted rock } \\
\text { mass, } \mathbf{1 0}^{\mathbf{6}} \mathbf{~ m}^{\mathbf{3}}\end{array}$} & \multicolumn{4}{|c|}{ The average duration of downtime for } \\
& $\begin{array}{c}\text { the sho- } \\
\text { vels's } \\
\text { park }\end{array}$ & $\begin{array}{c}\text { a sho- } \\
\text { vel }\end{array}$ & $\begin{array}{c}\text { the dump } \\
\text { truck's } \\
\text { park }\end{array}$ & $\begin{array}{c}\text { for a } \\
\text { dump } \\
\text { truck }\end{array}$ \\
\hline 13.85 & 664 & 83 & 1560 & 48.1 \\
\hline 14.36 & 722 & 92.5 & 1650 & 66 \\
\hline 14.91 & 765 & 95.6 & 1860 & 86.5 \\
\hline 14.988 & 770 & 96.2 & 1905.7 & 19.8 \\
\hline 15.003 & 765 & 109.2 & 2100 & 87.8 \\
\hline 15.556 & 811 & 101.3 & 2422.8 & 101.3 \\
\hline 15.7 & 825 & 91.66 & 2350 & 97.9 \\
\hline 16.105 & 865 & 96.1 & 2613 & 115.5 \\
\hline
\end{tabular}

The blasting work is carried out once a week on the Erdenet surface mine, so approximately 52 times per year. 
The duration of downtime due to blasting operation depends on the volume of the rock to be blasted per year on the one hand, and the number of blasts per year on the other, i.e. the time between two consecutive blasting works.

The volume of the blasted rock will change with the increase and decrease of the annual open-pit work. Based on the study, the duration of downtime of the shovels and the dump trucks at the Erdenet surface mine due to the blasting will be considered depending on the volume of the rock mass that will blast per year for their park.

A regression correlation (Figure 4) between the duration of downtime for shovel's park and dump truck's park during the year and the volume of the blasted rock in a given year was established and analyzed using statistical software.
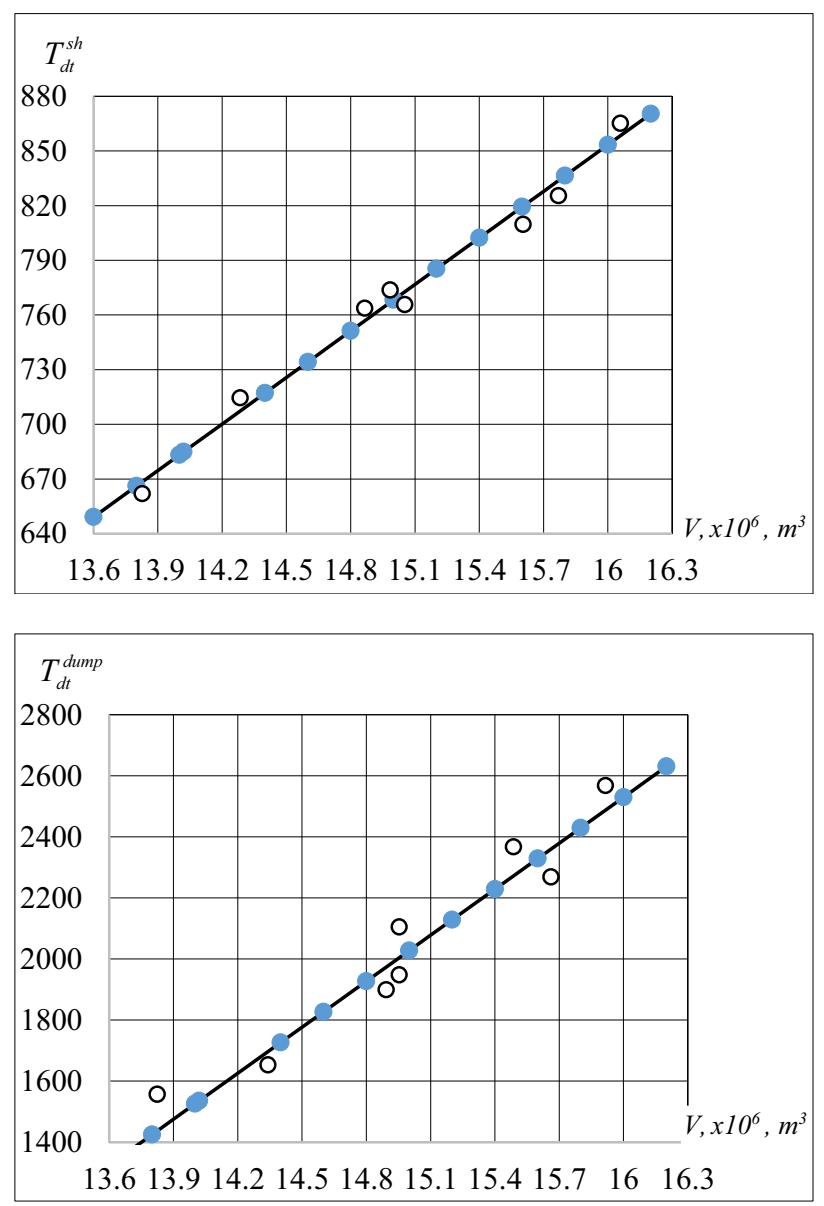

Fig. 4. Correlation between mine equipment downtime and blasting rock mass: for shovels's park; b. for dump truck's park

As a result, the relationship between the volume of the rock mass to be blasted per year and the downtime due to blasting operations:

for shovel's park:

$$
T_{d t}^{s h}=-508.481+85.122 \mathrm{~V}, \quad \mathrm{r}=0.923
$$

for dump truck's park:

$$
T_{d t}^{\text {dump }}=-5503.82+502.1256 \mathrm{~V}, \quad \mathrm{r}=0.817
$$

There is a strong correlation between the parameters under consideration since the values of the correlation coefficients $\mathrm{r}=0.923$ and $\mathrm{r}=0.817$ for equations (1) and (2), which show the relationship between the duration of downtime of equipment park and the volume of blasting rock mass. For equations (1) and (2), when the probability is $95 \%$, the values of the Fisher test are F $(1.6)=42, F$ $(1.6)=37$, and the total error are 5.62, 7.8, indicating that the relationship is correct.

The number of blasting blocks will be determined by the volume of the rock mass to be excavated during the year. By reducing the number of blasting per year and optimizing them, it is possible to decrease the downtime of shovels, dump trucks, and other machinery used at the mine. As result, this will allow them to improve their work to a certain extent.

Therefore, it is necessary to define the optimal number of blasting per year. The mining machine's production is limited by the shovel's production, which is the head mining equipment. Hence, it is essential to determine the number of blasting per year and the volume of rock to be blasted once concerning the shovel's operation.

The purpose of preparing the rock for excavation is to ensure the continuous operation of the shovel. Therefore, based on the theory of supply or resource allocation, let's determine the volume of a one-time blasting by dynamic programming.

The purpose of resource allocation theory is to determine the optimal amount of product supply (S), average resource level (Sd), inter-supply time, or supply rotation interval $(\mathrm{t})$ depending on the level of consumer demand and supply. In resource management theory, the following conditions are considered in several variants [9]. These include:

$\checkmark$ reserve intervals are different, and the amount of supply is constant;

$\checkmark$ backup rotation interval and reserve size are variable;

$\checkmark$ reserve turnover intervals are regular, and resource supply is unstable.

The basic condition for operating shovels and dump trucks with a regular uniform load throughout the year is to provide them with a constant supply of blasted rock at regular intervals (Figure 5).

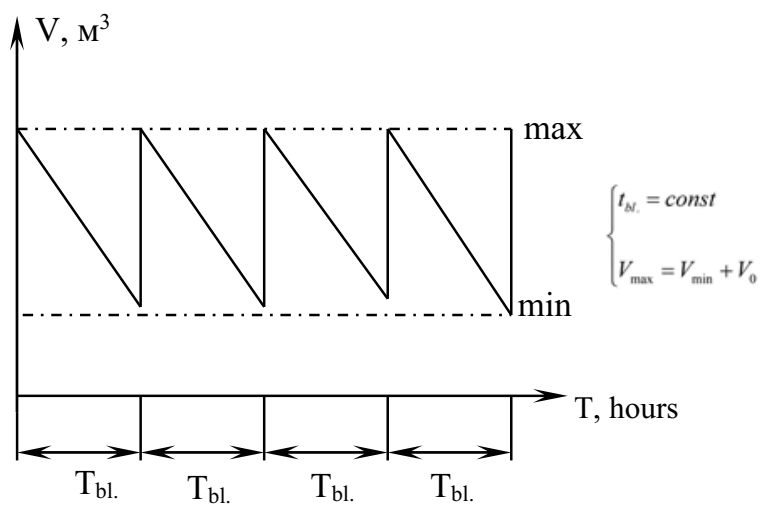

Fig. 5. Distribution of to be blasted the rock mass resources. 


\section{Result and discussion}

In practice, the condition that the supply is regular when the supply time interval is regular is satisfied when the demand does not fluctuate over time. In our case, the number of equipment available may be uneven during the supply period due to maintenance and repair. Therefore, it is appropriate to consider the volume of the blasting rock mass or the volume of excavation and transporting resources between the minimum and maximum values required.

In this case, the volume of reserve to be prepared varies from the minimum to the maximum, depending on the demand for the supply (the blasting rock mass) in a given interval (the time between two consecutive blasts or the frequency of blast). In other words, the values of the maximum number of shovels to be available and the minimum number of resources to be prepared in the interval between the supply of the reserve are determined.

The time between the two blasts, or the reserve rotation interval, is given by the following formula, which is the average daily output of the shovels working on the bench and the ratio of the rock mass on the bench to be ready for excavation.

$$
t_{b l .}=\frac{V_{j}}{Q_{s h}^{j}}
$$

where: $j$ - the number of benches where shovels is in operation, $V_{j}$ - the volume of the blasted rock mass on the $j$ bench, $\mathrm{m}^{3} ; Q_{s h}^{j}$ - average daily output of shovel, $\mathrm{m}^{3} /$ hour.

The number $N_{\text {year }}$ of blasting per year, expressed in terms of the volume of the rock mass to be blasted during the year $V_{\text {year }}$ and one time $V_{0}$, is expressed as follows.

$$
N_{\text {year }}=\frac{V_{\text {year }}}{V_{0}}
$$

where: $V_{\text {year }}$ - the volume of the rock mass to be blasted per year, $\mathrm{m}^{3} ; V_{0}$ - volume of one time blasting, $\mathrm{m}^{3}$.

The purpose of blasting is to distribute the blasting block $\mathrm{N}$ times a year in order to minimize equipment downtime. By reducing the number of blasting per year, it is possible to decrease downtime of equipment and to reduce the lost of productivity of equipment due to blasting work [7, 8]. However, as this increases the size of one time blasting, the cost of one-time blasting will increase, and the optimal number of blasting per year will be found at the lowest downtime of equipment and blasting costs.

To simplify the task of optimizing the number of blasting per year, or the volume of one-time blasting, we assume that the volume of blasting is regular for a given year. From this, it can be assumed that the average volume of one-time blasting is regular. Therefore, the linear model for optimizing the number of blasting per year by the cost of blasting operations can be formulated as follows, taking into account the deviation of the value of the resource allocation from the minimum to the maximum value and formula (4).

$$
Z\left(V_{0}, t\right)=\frac{V_{\max }}{V_{\min }}=\left(N \bar{V} C_{b l . o p}+\frac{V_{\text {year }}}{\bar{V}} T_{\text {d.t }} C_{\text {l.d.t }}\right)
$$

where: $N$ - number of blasting per year; $T_{d . t}=n t_{i}$ duration of shovel's downtime due to blasting work; $C_{\text {l.d.t }}$ - loss per hour of shovel's down time, USD/hour; $C_{b l . o p}$ cost of blasting one cubic meter of rock mass, USD $/ \mathrm{m}^{3}$.

Based on the modeling equation (5) for optimizing the number of blasting per year, we can say that the actual blasting cost will increase directly by the volume of the blasting block, and the downtime of equipment will be a hyperbola type and located in the first quadrant of the coordinate plane.

Therefore, the volume of one tome blasting rock mass or solution of the equation is determined by the intersection of the straight line represented by the first addend of equation (5) and the hyperbolic represented by the second addend. Our task is one-dimensional because the blasting block for one time or resource distribution is a one-time allocation, and resource allocation is a multistep static decision-making process. Instead, the decision and state vectors for each stage are one-dimensional. Therefore, let's optimize the linear model (5) by dynamic programming.

To do this, consider the number of blasting per year as a step in the decision-making process and let's transform the modeling equation expressed by equation (5) in the following order.

Divide the volume of the rock mass to be blasted or the annual reserve $V_{\text {year }}$ required for shovels and dump trucks into $V_{0}^{i} \mathrm{i}=1,2, \ldots, \mathrm{N}$ sub-sets of one-time blasting. The cost $z\left(V_{0}^{i}\right)$ of the resource or cost of the blasting rock mass, the downtime (t) of the equipment and downtime loss $z\left(t^{i}\right)$ are attended for each $V_{0}^{i}$.

Therefore, the cost of blasting during a given year can be given by the sum function:

$$
Z\left(V_{0}^{1}, \mathrm{t}^{1}, \ldots V_{0}^{N}, \mathrm{t}^{\mathrm{N}}\right)=\left(\sum_{i=1}^{N} z\left(V_{0}^{i}\right)+\sum_{i=1}^{N} z\left(t^{i}\right)\right)
$$

and the amount of resource to be used, or the volume of rock to be blasted per year, is expressed by the formula:

$$
V_{\text {year }}=\sum_{i=1}^{N} V_{0}^{i}
$$

and the following condition are met.

$$
V_{0}^{i}>0
$$

Therefore, the task of optimizing the number of blasting per year is determined by a mathematical model expressed by the following equation with the objective of minimizing blasting costs.

$$
\begin{gathered}
Z\left(V_{0}^{1}, \mathrm{t}^{1}, \ldots V_{0}^{N}, \mathrm{t}^{\mathrm{N}}\right)=\left(\sum_{i=1}^{N} z\left(V_{0}^{i}\right)+\sum_{i=1}^{N} z\left(t^{i}\right)\right) \rightarrow \min \\
V_{\text {year }}=\sum_{i=1}^{N} V_{0}^{i}, \mathrm{~V}_{0}^{\mathrm{i}}>0
\end{gathered}
$$


The first addend of equation (9) is expressed the volume of the rock mass to be blasted at one time and the cost of the blasting rock mass for $1 \mathrm{~m}^{3}$. Loss of production due to downtime of the shovels' park is expressed as the number of not working machines and their downtime. So, equation (9) can be written in the following form.

$Z\left(V_{0}^{1}, \mathrm{t}^{1}, \ldots V_{0}^{N}, \mathrm{t}^{\mathrm{N}}\right)=\left(\sum_{i=1}^{N}\left(V_{0}^{i} C_{\text {bl.op }}\right)+\sum_{i=1}^{N}\left(n t_{i} C_{\text {l.d.t }}\right)\right) \rightarrow \min$

where: $n$ - the number of not working shovelss during $\mathrm{i}$ blasting due to blasting work; $t_{i}$-duration of $\mathrm{i}$ blasting work or duration of downtime time for one machine due to blasting; - loss of shovel's downtime for per hour, USD/hour; $V_{0}^{i}$ - volume of rock mass to be fragmented during i blasting work, $\mathrm{m}^{3} ; C_{b l . o p}$ - cost of blasting for one cubic meter of rock mass, USD/m3.

At the beginning of the resource allocation, $i$ at the beginning of the process, the amount of resources allocated is $V_{0}^{i}=0$, and at the end of the allocation, $V_{0}^{i}=V_{\text {yeat }}^{i}$. Therefore, since the state space is onedimensional, as described above, there will be only $s_{0}=0$ and $s_{N}=V_{\text {year }}$ at the beginning and end of the distribution, and during the distribution the state $s_{0}$ will be transformed to the $s_{N}$ state under optimization conditions. We divide the interval $[0, \mathrm{~N}]$ into sub-intervals $\mathrm{E}$, or construct decision sub-spaces, to select the amount of work to be done in a single blast.

Dividing the interval $[0, \mathrm{~N}]$ into sub-intervals will make the problem discrete, and the problem will be easier if we choose the same length $\Delta$ of the interval as shown in Figure 2. The length of the interval can be $\bar{V}=\frac{V_{\max }+V_{\min }}{2}$ as shown in Figure 2 .

Thus, the modeling has been developed to manage the supply of shovels and dump trucks with the fragmented rock mass by dynamic programming, which allows reducing the downtime due to blasting of all mining equipment, thus ensuring the lowest cost and normal operation of loading, transportation operations. Accordingly, the above-explained task for determining the blasting period is a significant solution to determine how the process interacts with the excavation and hauling operations. This ensures that the digging and transporting process can be operated efficiently at the lowest possible cost.

\section{Conclusions}

According to a study at the Erdenet open-pit mine, as the mine's capacity enlarges, the stripping, extraction, and the volume of blasting work rises each year. As a result, equipment downtime increases, and performance losses increase. In particular, it has been defined that the downtime of the mining equipment increases linearly as the volume of the rock mass to be blasted per year increases.
Therefore, the study shows that the problem can be completely solved by managing the volume of one-time blasting and the time between explosions.

By optimizing the time between blasting through dynamic programming, it is possible to reduce the direct and indirect costs associated with blasting.

\section{References}

1. Nanzad Ts., Development of ways to reduce the cost of mining rock masses by quarry excavators. (Ulaanbaatar 2013)

2. Nanzad Ts. Excavator operation quality management. (Ulaanbaatar 2013)

3. Jim McCalley., Yong Jiang., Vasant Honavar, Jyotishman Pathak. and others. Automated Integration of Condition Monitoring with an Optimized Maintenance Scheduler for Circuit Breakers and Power Transformers. (PSERC Publication 2006)

4. Ji Q. and Sanford R. L. Autonomous excavation of fragmented rock using machine vision. (Society for Mining, Metallurgy \& Exploration Inc., Littleton CO, U.S.A., 1993)

5. Takahashi H., Kamata H., Masuyama T., and Sarata S. Autonomous shoveling of rocks by using image vision system on LHD. International Conference on Mine Mechanization \& Automation, 1.33-1.44, (1998)

6. Khavalbolot K., Mining logistics. (Ulaanbaatar 2009)

7. Karamia A., Afiuni-Zadehb S. Sizing of rock fragmentation modeling due to bench blasting using adaptive neuro-fuzzy inference system and radial basis function. Int. J of Min. Sc. \& Tech.; 22, 459463 (2012)

8. Selamet G.. Ercelebi. Optimization of shovel-truck system for surface mining. J South A. Ins. of Min. \& Met. 109(7), 433-439

9. Stephen Aro-Gordon, Jaydeeo Anil Gupte. Review of modern inventory management techniques. Gl. J of Bus. \& Man. 1.

10. E. Alaphia Wright. The use of dynamic programming for open pit mine design: Some practical implications. Min. Sc. \& Tech. 4, 97-104 (1987)

11. V. Peregudov, I. Hryhoriev, S. Joukov, Y. Hryhoriev. Determination of the transfer step of the ore chute while mining the technogenic deposit of the bulk type. E3S Web of Conferences, 166, 02004 (2020)

12. V. Azarian, S. Lutsenko, S. Zhukov, A. Skachkov, R. Zaiarskyi, D. Titov. Applied scientific and systemic problems of the related ore-dressing plants interaction in the event of decommissioning the massif that separates their quarries. Min. of Miner. Dep., 14(1), 1-10 (2020)

13. Z. Malanchuk, V.Moshynskyi, Ye. Malanchuk, V. Korniienko, M.Koziar. Results of Research into the Content of Rare Earth Materials in Man-Made 
Phosphogypsum Deposits. Key Engineering Materials, (844), 77-87 (2020)

14. Z. Malanchuk, V. Korniienko, Ye. Malanchuk, V. Soroka, O. Vasylchuk. Modeling the formation of high metal concentration zones in man-made deposits. Mining of Mineral Deposits, 12(2), 76-84 (2018)

15. V. Naduty, Z. Malanchuk, Y. Malanchuk, V. Korniienko. Research results proving the dependence of the copper concentrate amount recovered from basalt raw material on the electric separator field intensity. E. - Eur. J of Ent. Tech. / PC «Technology Center», Kharkiv, Ukraine, Volume 5/5(83), 19-24 (ISSN 1729-3774, UDC 622.277 2016) 